\title{
A Cascaded Converter Interfacing Long Distance HVDC and Back-to-Back HVDC Systems
}

\author{
Wang Xiang, Member, IEEE, Ruizhang Yang, Chang Lin, Jiapei Zhou, Jinyu Wen, Member, IEEE, Weixing Lin, Member, IEEE
}

\begin{abstract}
This paper proposes a cascaded converter dedicated to long-distance HVDC infeed and asynchronous back-to-back interconnection of receiving grids. The cascaded converter is consisted of MMCs in series and parallel connection, meeting the high DC voltage and power demand of HVDC system. It realizes hierarchical feeding and asynchronous interconnection of receiving grids, optimizing the multi-infeed short circuit ratio and improving the flexibility of the receiving grids. The topology and operating characteristics of the cascaded converter are introduced in detail. The multi-infeed short-circuits ratio (MISCR) and the maximum power infeed of the cascaded converter based HVDC systems are analyzed. Various feasible operating modes with online switching strategies of the cascaded converter are studied to improve the operational flexibility of the system. The simulation results verify the effectiveness of the control strategy of the HVDC system embedding the cascaded converter. The DC faults clearing strategy and operating modes switching strategies are also validated.
\end{abstract}

Index Terms - HVDC transmission, modular multilevel converter, asynchronous interconnection, hierarchical connection, multi-infeed short circuit ratio.

\section{INTRODUCTION}

High voltage direct current (HVDC) transmission technology is an efficient approach to deliver bulk renewable power over long distance [1][2]. As the increased commission of line-commutated converter (LCC) based HVDC projects, two or more HVDC links tend to feed into one regional power grid and form a multi-infeed HVDC system, such as the East China Power Grid and the Southern China Power Grid. In such a system, the mutual interactions between the different HVDC links bring a number of operating problems in receiving grids, such as high short circuit current, voltage instability, and concurrent commutation failure of converters, particularly when feeding into a weak AC grid [3].

To address the issue brought by multi-infeed HVDC, many solutions have been proposed, which can be classified into two types. One is to improve the topology of inverters, such as

This work is sponsored by the State Grid Corporation of China Science and Technology Project (Research on Key Technologies of Multi-infeed Cascaded Hybrid HVDC Transmission System). (Corresponding author: Ruizhang Yang)

W. Xiang, R. Yang, J. Wen are with the State Key Laboratory of Advanced Electromagnetic Engineering and Technology, Huazhong University of Science and Technology, Wuhan 430074, China. (e-mail: xiangwang1003@foxmail.com, yangruizhang@hust.edu.cn, jinyu.wen @hust.edu.cn).

C. Lin, J. Zhou are with the Global Energy Interconnection Research Institute Co., Ltd., Changping District, Beijing 102209, China. (e-mail: 121058204@qq.com, cathy_zhou0411@foxmail.com).

W. Lin is with the TBEA Sunoasis CO., LTD., Urumchi, 830011, China. (e-mail: weixinglin@foxmail.com) applying the voltage source converters (VSC) at the inverter side to mitigate the problem of commutation failure. The other one is to optimize the structure of the receiving grids, such as hierarchical connection to receiving grids for the LCC-HVDC systems or adopting the back-to-back HVDC system to asynchronously interconnect receiving grids.

For the first approach, references [4][5] adopt the modular multilevel converter (MMC) at inverter side and LCC at rectifier side, combining the merits of $\mathrm{LCC}$ and $\mathrm{MMC}$ converters. This two-terminal hybrid HVDC system avoids commutation failure caused by LCC inverter and can connect to a weak AC system. To deal with DC faults, high-power diodes can be installed at the DC terminal of MMC inverter to block DC fault currents [5]. With the development of MMC technologies, the full bridge MMC, the hybrid MMC consisted of full bridge sub-module and half bridge sub-module and the asymmetrical mixed MMC are also proposed as an inverter to deal with DC faults [6][7]. Considering a large amount of LCC-HVDC links are already existed, reference [8] uses MMCs to tap into an existing HVDC link to form a multi-terminal hybrid HVDC. References [9][10] use MMC-HVDC to tap into the same AC bus to form a dual infeed HVDC system. Since the typical DC voltage rating of LCC-HVDC $( \pm 800 \mathrm{kV})$ is higher than the MMC-HVDC system $( \pm 320 \mathrm{kV})$, reference [11] proposes a hybrid converter consisted of a series connection of MMC and LCC converters to match the DC voltages, combining the advantages of high voltage rating, low loss, relatively low cost of LCC and self-commutating of MMC.

However, since there are already many LCC-HVDC projects commissioned in the load centers, the above approach still cannot overcome the instability problem in the receiving power grids, especially when the receiving grid is subject to large disturbances, such as converter blocking [12]. Thus, many efforts have been made towards optimizing the structure of receiving power grids [12]-[17]. References [12]-[15] divide a large-scale synchronous AC network into two asynchronous sub-grids via back-to-back HVDC links, which optimizes the receiving system and effectively enhances the frequency stability. [16][17] propose a hierarchical connection mode (HCM) to improve the multi-infeed short circuit ratio (MISCR) for the ultra HVDC (UHVDC) systems. In such a system, different valves at the inverter are connecting to two AC systems with different voltage levels. The HCM can significantly improve the power infeed capability and the stability of the AC grids by reasonably dispatching power flow in the receiving grids. To date, the above two attempts have been applied to several practical projects, such as the HCM in the $\pm 1100 \mathrm{kV}$ Changji-Guquan UHVDC project and the asynchronous 
This paper is a post-print of a paper accepted for publication in IEEE Journal of Emerging and Selected Topics in Power Electronics and is subject to Institution of Electrical and Electronic Engineering Copyright. The copy of record is available at IEEE Xplore Digital Library

interconnection in the $\pm 350 \mathrm{kV}$ Luxi back-to-back HVDC project completed in 2016 [13] and the $\pm 450 \mathrm{kV} Y u-E$ back-to-back HVDC projects being completed in 2019 [14].

Thus, adopting MMC as an inverter and using back-to-back HVDC to partition the synchronous grid can effectively solve the problems in receiving grids. However, it requires the construction of multiple converter stations in receiving grids. Namely, one station for long distance HVDC infeed and the other station for back-to-back HVDC systems, which imposes substantial economic costs on land resources and construction investment at developed load centers.

Therefore, a cascaded converter topology is proposed in this paper. The cascaded converter combines the technical merits of the hybrid HVDC transmission system and the back-to-back HVDC system, achieving large remote renewable energy transmission and HVDC hierarchical connection to receiving grids as well as the asynchronous interconnection of receiving grids. It can reduce the total capacity of converters and capital cost. The high short circuit fault current, commutation failure problems brought by the multi-infeed UHVDC can be effectively solved at a lower cost.

The remainder of this paper is organized as follows. Firstly, the topology and operation principle of the cascaded converter is introduced in section II. Then, the operational improvements of the cascaded converter on receiving grids are analyzed in section III. Section IV presents the control strategy and the DC fault clearing strategy. Section V studies the operating modes of the cascaded converter based HVDC system. The extended topologies for other operating requirements are elaborated in section VI. The simulation validation and conclusions are conducted in section VII and VIII.

\section{TOPOLOGY AND THE CASCADED CONVERTER}

\section{A. Topology of the Cascaded Converter}

The circuit configuration of the cascaded converter is depicted in Fig. 1. It consists of an upper sub-converter MMC1 and two lower sub-converters MMC2 and MMC3. The upper valve and lower valves are connected in series, of which the lower valves are in parallel. MMC1 and MMC3 are hierarchically interfaced to Grid 1 and Grid 1'. Where Grid 1 and Grid 1' are two sub-systems with different voltage ratings in one synchronous AC power grid. $T_{r}$ represents the transformer between the two sub AC systems. MMC2 is interfaced to an asynchronous grid (Grid2). Thus, Grid 1 and Grid 2 are asynchronously interconnected by the lower back-to-back sub-converters MMC2 and MMC3. Based on the topology, the hierarchical connection to receiving grids and asynchronous interconnection can be achieved at the same time.

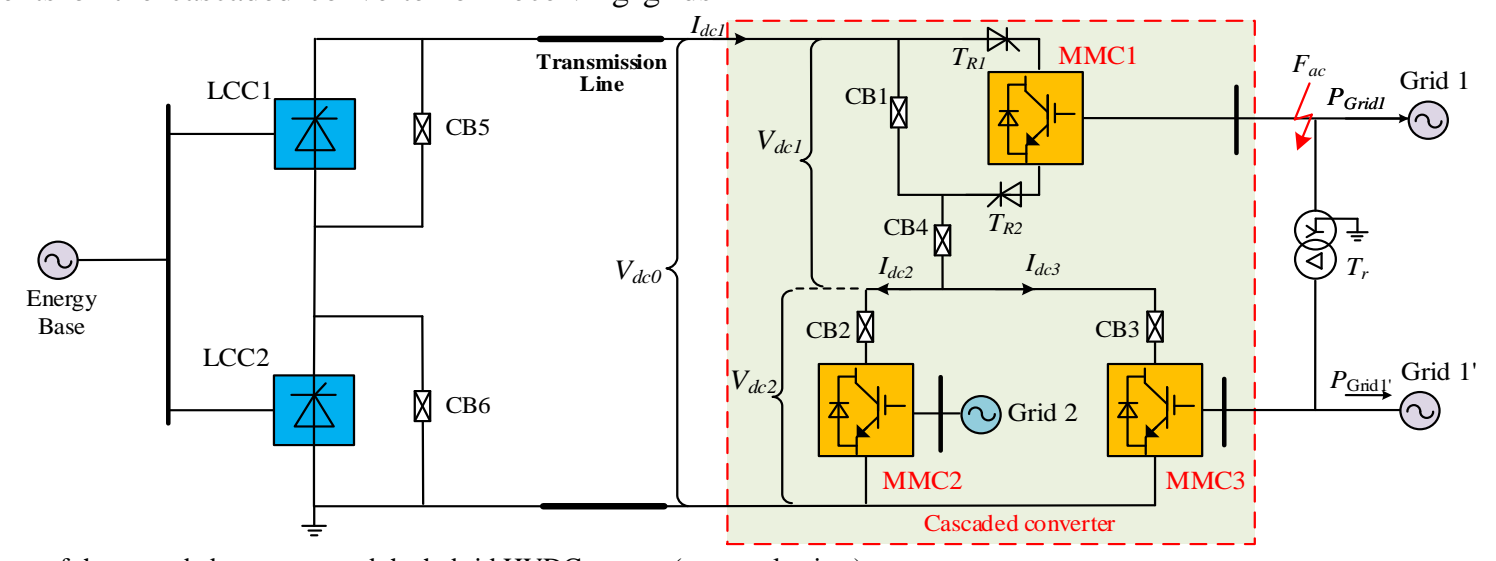

Fig. 1. Structure of the cascaded converter and the hybrid HVDC system (monopole view).

The cascaded converter has multiple operating modes. When any of the sub-converters quits operation during faults or maintenances, the converter can be switched to a new operation mode by coordination control of thyristors $T_{R i}$ (i=1-2) and bypass breakers $\mathrm{CB}_{j}(j=1-6)$, ensuring a certain power transmission in specific conditions.

\section{B. Economic Evaluation of the Cascaded Converter}

Fig. 2 shows two schemes that can realize long distance HVDC infeed and asynchronous interconnection of the receiving grids.

Fig. 2 (a) is the conventional scheme, where station A located in Grid 1 is the inverter of the long distance HVDC system and station B constitutes the back-to-back HVDC system. Fig. 2 (b) is the scheme based on the cascaded converter. The long distance HVDC system is tapped into the back-to-back HVDC system.
Denote the transmitted power of long distance HVDC system as $P_{L}$, the exchange power from Grid 1 to Grid 2 as $P_{B}$, the DC voltage of the long distance HVDC system is $V_{d c} 0$ and the DC voltages of the high and low valves are $V_{d c l}$ and $V_{d c 2}$ respectively $\left(V_{d c l}=V_{d c 2}\right)$.

Referring to Fig. 2 (a), $P_{L}$ is fed into Grid 1 via an AC/DC conversion. $P_{B}$ is transmitted to Grid 1 via an $\mathrm{AC} / \mathrm{DC} / \mathrm{AC}$ conversion. Thus, the total capacity $\left(P_{\Sigma 1}\right)$ of converters is

$$
P_{\Sigma 1}=P_{L}+2 P_{B}
$$

Referring to Fig. 2 (b), $P_{\mathrm{L}}$ is directly fed into the back-to-back HVDC system. The active power $\left(P_{d i}\right)$ and current $\left(I_{d c i}\right)$ of each sub-converter satisfies

$$
\left\{\begin{array}{l}
V_{d c 0}=V_{d c 1}+V_{d c 2}, \quad I_{d c 1}=I_{d c 2}+I_{d c 3}, \quad P_{d i}=V_{d c i} I_{d c i} \\
P_{L}=V_{d c 0} I_{d c 1}=P_{d 1}+P_{d 2}+P_{d 3}
\end{array}\right.
$$

The capacity of each sub-converter can be obtained. 
This paper is a post-print of a paper accepted for publication in IEEE Journal of Emerging and Selected Topics in Power Electronics and is subject to Institution of Electrical and Electronic Engineering Copyright. The copy of record is available at IEEE Xplore Digital Library

$$
\left\{\begin{array}{l}
P_{d 1}=\frac{V_{d c 1}}{V_{d c 1}+V_{d c 2}} P_{L}, \quad P_{d 2}=P_{B} \\
P_{d 3}=V_{d c 2}\left(\frac{P_{L}}{V_{d c 1}+V_{d c 2}}-\frac{P_{B}}{V_{d c 2}}\right)
\end{array}\right.
$$

Then, the total capacity $\left(P_{\sum 2}\right)$ of the sub-converters is

$$
P_{\Sigma 2}=P_{d 1}+P_{d 2}+P_{d 3}=P_{L}
$$

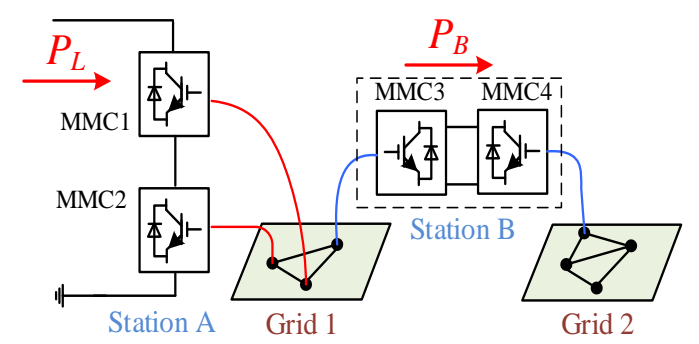

(a) Conventional HVDC infeed and back-to-back interconnection

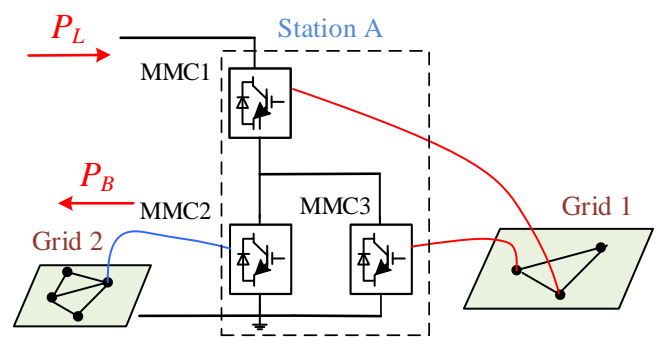

(b) Scheme based on the proposed cascaded converter

Fig. 2. Schemes of long distance HVDC and asynchronous interconnection.

Comparing equation (1) with (4), it can be seen that the capacity of the cascaded converter is less than that of the conventional scheme. Supposing the total power delivered by the long distance HVDC system is $3000 \mathrm{MW}$ and the exchange power fed into Grid 2 is $750 \mathrm{MW}$. The total capacity of the cascaded converter scheme is $3000 \mathrm{MW}$. While the converter capacity using the conventional scheme is $4500 \mathrm{MW}$, which is 1.5 times larger than the cascaded converter scheme. Thus, it can be concluded that the cascaded converter can significantly reduce the converter capacity, thus reduce the cost and footprint.

\section{OPERATIONAL CHARACTERISTICS OF THE RECEIVING GRIDS EMBEDDING CASCADED CONVERTER}

\section{A. Analysis of Multi-Infeed Short Circuit Ratio}

To analyze the strength of the receiving grids embedding cascaded converter, the multi-infeed short circuit ratio is considered [18]. The equivalent circuit of the receiving grids is shown in Fig. 3. Grid 1 and Grid 2 are asynchronously interconnected by MMC2 and MMC3. The synchronous networks Grid 1 and Grid 1' are connected by an AC transformer. The $\mathrm{AC}$ bus nodes are also shown in Fig. $3 Z_{\text {ii }}$ $(\mathrm{i}=1,2,3)$ is the equivalent system impedance. $Z_{13}$ is the equivalent impedance of the $\mathrm{AC}$ transformer and the interconnection lines between bus 1 and $3 ; k$ is the turns-ratio.

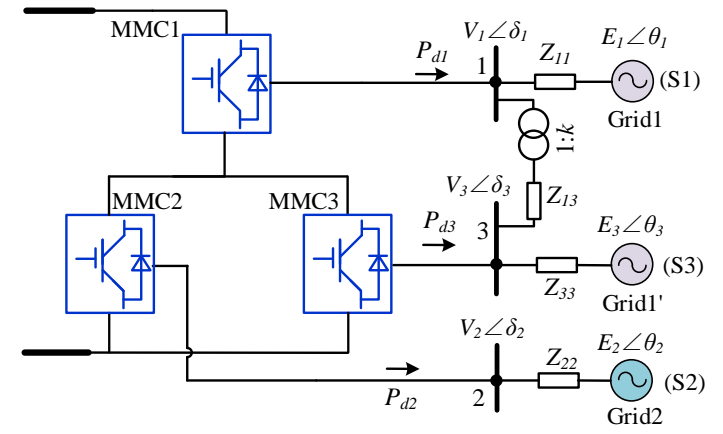

Fig. 3. Equivalent AC circuit of the receiving grids.

The equivalent impedance matrix $\mathrm{Z}$ aligned with each $\mathrm{AC}$ bus node of the receiving grids can be calculated as

$$
Z=\left[\begin{array}{ccc}
\frac{Z_{11} Z_{13}+Z_{11} Z_{33}}{Z_{11}+Z_{13}+Z_{33}} & 0 & \frac{Z_{11} Z_{33}}{Z_{11}+Z_{13}+Z_{33}} \\
0 & Z_{22} & 0 \\
\frac{Z_{11} Z_{33}}{Z_{11}+Z_{13}+Z_{33}} & 0 & \frac{Z_{33} Z_{13}+Z_{11} Z_{33}}{Z_{11}+Z_{13}+Z_{33}}
\end{array}\right]
$$

Denote that $Z_{\text {eqii }}$ is the self-impedance of $\mathrm{AC}$ bus $i$, corresponding to the unit at $i$-th row and $i$-th column in matrix $Z$. $Z_{\text {eqij }}$ is the mutual impedance of bus $i$ interacted with bus $j$, corresponding to the unit at $i$-th row and $j$-th column in matrix $Z$. The multi-infeed short circuit ratio (MISCR) of bus $i$ can be calculated as follows.

$$
\begin{aligned}
\operatorname{MISCR}_{i} & =\frac{S_{a c i}}{P_{d i}+\sum_{j=1, j \neq i}^{n} \frac{\Delta V_{j}}{\Delta V_{i}} P_{d j}}=\frac{V_{i}^{2} / Z_{e q i i}}{P_{d i}+\sum_{j=1, j \neq i}^{n}\left|\frac{Z_{e q i j}}{Z_{e q i i}}\right| P_{d j}} \\
& =\frac{V_{i}^{2}}{\left|Z_{e q i i}\right| P_{d i}+\sum_{j=1, j \neq i}^{n}\left|Z_{e q i i}\right| P_{d j}}
\end{aligned}
$$

where $V_{i}$ is the voltage of $\mathrm{AC}$ bus $i . \Delta V_{i}$ is the voltage variation on $\mathrm{AC}$ bus $i ; \Delta V_{j}$ is the voltage variation on bus $j$ caused by the voltage variation on bus $i . \Delta V_{j} / \Delta V_{i}$ represents the coupling effect between bus $i$ and $j$. $S_{a c i}$ is the short circuit capacity of the receiving system $S_{i} . P_{d i}$ and $P_{d j}$ are the rated infeed DC power at bus $i$ and $j$.

Denote that the base voltage of each sub-system is its rated voltage. Under rated operation, equation (6) can be simplified in per-unit form.

$$
\operatorname{MISCR}_{i}^{p u}=\frac{1}{\left|Z_{e q i i}\right| P_{d i}+\sum_{j=1, j \neq i}^{n}\left|Z_{e q i j}\right| P_{d j}}
$$

The equivalent system impedance of bus $i$ can be therefore calculated as

$$
Z_{e q i}=\left|Z_{e q i i}\right|+\sum_{j=1, j \neq i}^{n}\left|Z_{e q i j}\right| \frac{P_{d j}}{P_{d i}}
$$

Table 1 shows the MISCR with different sub-converter capacity and system impedances under different HVDC infeed modes, such as HVDC with a single layer and hierarchical layers. Where the single layer mode represents that the long distance HVDC system is interfaced to an AC grid with a voltage rating of $1000 \mathrm{kV}$ or $500 \mathrm{kV}$. The 
hierarchical layers mode represents that the long distance HVDC system is interfaced to an AC grid with two different voltage ratings at the same time $(1000 \mathrm{kV}$ and $500 \mathrm{kV})$. In Table 1 , the interconnection impedance $Z_{13}$ is selected as $1 \mathrm{pu}$ according to [16]. Especially, for the analysis of performance under extreme weak $\mathrm{AC}$ grids, the equivalent system impedances of 1 and 1.5 are considered respectively [19]. The other parameters are listed in Table 4.

Table 1 MISCR of receiving systems with different infeed mode

\begin{tabular}{|c|c|c|c|c|}
\hline $\begin{array}{l}\text { Connection } \\
\text { mode }\end{array}$ & $\begin{array}{c}\text { Power } \\
\text { Distribution }\end{array}$ & $Z_{\mathrm{ii}} / \mathrm{pu}$ & $\begin{array}{l}\text { Voltage of AC } \\
\text { system } / \mathrm{kV}\end{array}$ & MISCR \\
\hline \multirow{4}{*}{$\begin{array}{l}\text { HVDC with } \\
\text { single infeed }\end{array}$} & 1 & $1 / 2$ & 500 & 2 \\
\hline & 1 & $1 / 3$ & 1000 & 3 \\
\hline & 1 & 1.5 & 500 & 0.667 \\
\hline & 1 & 1 & 1000 & 1 \\
\hline \multirow{4}{*}{$\begin{array}{l}\text { HVDC } \\
\text { hierarchical } \\
\text { infeed }\end{array}$} & \multirow{2}{*}{$0.5,0.5$} & $1 / 2$ & 500 & 3.84 \\
\hline & & $1 / 3$ & 1000 & 6.64 \\
\hline & \multirow{2}{*}{$0.5,0.5$} & 1.5 & 500 & 1.238 \\
\hline & & 1 & 1000 & 2.364 \\
\hline \multirow{30}{*}{$\begin{array}{l}\text { Cascaded } \\
\text { Converter }\end{array}$} & \multirow{3}{*}{$0.5,0.25,0.25$} & $1 / 3$ & $1000(\mathrm{~S} 1)$ & 8.500 \\
\hline & & $1 / 2$ & $500(\mathrm{~S} 2)$ & 8 \\
\hline & & $1 / 2$ & $500(\mathrm{~S} 3)$ & 6.182 \\
\hline & \multirow{3}{*}{$0.5,0.2,0.3$} & $1 / 3$ & $1000(\mathrm{~S} 1)$ & 8.94 \\
\hline & & $1 / 2$ & $500(\mathrm{~S} 2)$ & 6.667 \\
\hline & & $1 / 2$ & $500(\mathrm{~S} 3)$ & 7.084 \\
\hline & \multirow{3}{*}{$0.5,0.1,0.4$} & $1 / 3$ & $1000(\mathrm{~S} 1)$ & 9.999 \\
\hline & & $1 / 2$ & $500(\mathrm{~S} 2)$ & 5 \\
\hline & & $1 / 2$ & $500(\mathrm{~S} 3)$ & 10.00 \\
\hline & \multirow{3}{*}{$0.5,0.3,0.2$} & $1 / 3$ & $1000(\mathrm{~S} 1)$ & 8.095 \\
\hline & & $1 / 2$ & $500(\mathrm{~S} 2)$ & 10 \\
\hline & & $1 / 2$ & $500(\mathrm{~S} 3)$ & 5.484 \\
\hline & \multirow{3}{*}{$0.5,0.4,0.1$} & $1 / 3$ & $1000(\mathrm{~S} 1)$ & 7.392 \\
\hline & & $1 / 2$ & $500(\mathrm{~S} 2)$ & 20 \\
\hline & & $1 / 2$ & $500(\mathrm{~S} 3)$ & 4.474 \\
\hline & \multirow{3}{*}{$0.5,0.25,0.25$} & 1 & $1000(\mathrm{~S} 1)$ & 3.250 \\
\hline & & 1.5 & $500(\mathrm{~S} 2)$ & 1.926 \\
\hline & & 1.5 & $500(\mathrm{~S} 3)$ & 2.333 \\
\hline & \multirow{3}{*}{$0.5,0.2,0.3$} & 1 & $1000(\mathrm{~S} 1)$ & 3.023 \\
\hline & & 1.5 & $500(\mathrm{~S} 3)$ & 1.733 \\
\hline & & 1.5 & $500(\mathrm{~S} 2)$ & 3.333 \\
\hline & \multirow{3}{*}{$0.5,0.1,0.4$} & 1 & $1000(\mathrm{~S} 1)$ & 2.653 \\
\hline & & 1.5 & $500(\mathrm{~S} 3)$ & 1.445 \\
\hline & & 1.5 & $500(\mathrm{~S} 2)$ & 6.667 \\
\hline & \multirow{3}{*}{$0.5,0.3,0.2$} & 1 & $1000(\mathrm{~S} 1)$ & 3.514 \\
\hline & & 1.5 & $500(\mathrm{~S} 3)$ & 2.167 \\
\hline & & 1.5 & $500(\mathrm{~S} 2)$ & 2.222 \\
\hline & \multirow{3}{*}{$0.5,0.4,0.1$} & 1 & $1000(\mathrm{~S} 1)$ & 4.194 \\
\hline & & 1.5 & $500(\mathrm{~S} 3)$ & 2.889 \\
\hline & & 1.5 & $500(\mathrm{~S} 2)$ & 1.667 \\
\hline
\end{tabular}

According to Table 1, under the circumstances of same system impedances, the receiving grids adopting cascaded converter increase the MISCR and reduce the short circuit capacity compared with the other infeed modes. Referring to rows 4-5, 8-9, and 25-27, it can be found that the cascaded converter based system has a better performance on MISCR under weak AC grids. For the system embedding cascaded converter, Table 1 also indicates that by the reasonable design of capacity of sub-converters, the DC power fed into the AC grids can be optimized. Thus, the overall stability of the whole receiving system can be improved.

\section{B. Analysis of Maximum Active Power Infeed}

In Fig. 3, $E_{i}$ is the electromotive force of each sub-grid. Then, the active and reactive power for each converter can be expressed as

$$
\left\{\begin{array}{l}
P_{M M C i}=\frac{V_{i}^{2}}{\left|Z_{e q i}\right|} \cos \theta_{i}-\frac{E_{i} V_{i}}{\left|Z_{e q i}\right|} \cos \left(\delta_{i}+\theta_{i}\right) \\
Q_{M M C i}=\frac{V_{i}^{2}}{\left|Z_{e q i}\right|} \sin \theta_{i}-\frac{E_{i} V_{i}}{\left|Z_{e q i}\right|} \sin \left(\delta_{i}+\theta_{i}\right)
\end{array}\right.
$$

Supposing $V_{i}=E_{i}$, equation (9) can be simplified in per-unit form.

$$
\left\{\begin{array}{l}
P_{M M C i_{-} p u}=2 M I S C R_{i} \sin \frac{\delta_{i}}{2} \sin \left(\theta_{i}+\frac{\delta_{i}}{2}\right) \\
Q_{M M C i_{-} p u}=-2 M I S C R_{i} \sin \frac{\delta_{i}}{2} \cos \left(\theta_{i}+\frac{\delta_{i}}{2}\right) \\
M I S C R_{i}=\frac{V_{i}^{2}}{|Z e q i| P_{d i}}
\end{array}\right.
$$

The capacity constraint of each converter is

$$
P_{M M C i_{-} p u}^{2}+Q_{M M C i_{-} p u}^{2} \leq S_{\max }^{2}
$$

Combining (10) and (11), the maximum infed active power of the inverter at each $\mathrm{AC}$ bus can be obtained.

$$
P_{M M C i \max }=\left\{\begin{array}{c}
\frac{S_{\max }^{2}}{2 M I S C R_{i}}\left[\cos \theta_{i}+\sin \theta_{i} \sqrt{\left.\left(\frac{2 M I S C R_{i}}{S_{\max }}\right)^{2}-1\right]},\right. \\
M I S C R_{i}>\frac{S_{\max }}{\sqrt{2\left(1+\cos \theta_{i}\right)}} \\
\operatorname{MISCR}_{i}\left(\cos \theta_{i}+1\right), M I S C R_{i} \leq \frac{S_{\max }}{\sqrt{2\left(1+\cos \theta_{i}\right)}}
\end{array}\right.
$$

When $S_{\max }=1.12\left(P_{p u}=1, Q_{p u}=0.5\right)$, the maximum infed active power of the converter versus different system angles can be obtained as shown in Fig. 4. It can be seen that with the increase of MISCR, the maximum infed power increases. It is because when interfaced to a weak AC system (low MISCR), MMC should provide more reactive power to compensate for the voltage drop during active power transmission.

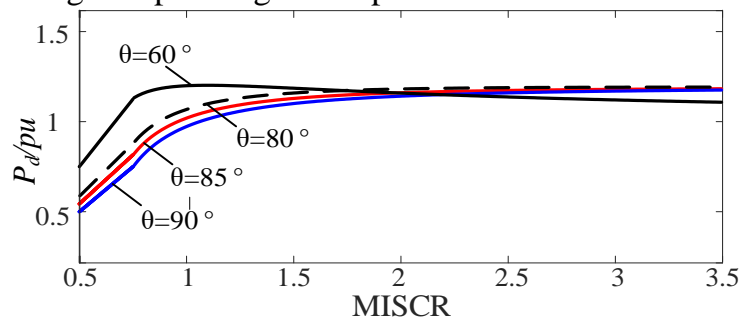

Fig. 4. Maximum power of converters versus MISCR and system angles.

Taking the cases shown in rows 4-5, 8-9, and 25-27 into consideration, the maximum infeed active power versus different infeed modes can be obtained, as shown in Table 2, where the system phase angle is $85^{\circ}$.

Table 2 The maximum power infeed versus different infeed mode.

\begin{tabular}{c|c|c|c|c}
\hline Infeed mode & $\begin{array}{c}\text { Power } \\
\text { Distribution }\end{array}$ & $\begin{array}{c}\text { AC Bus } \\
\text { Voltage } / \mathrm{kV}\end{array}$ & MISCR & $\begin{array}{c}\text { Maximum } \\
\text { power }\end{array}$ \\
\hline $\begin{array}{c}\text { Single } \\
\text { infeed }\end{array}$ & 1 & 500 & 0.667 & 0.688 \\
\cline { 2 - 5 } & 1 & 1000 & 1 & 0.979 \\
\hline $\begin{array}{c}\text { hierarchical } \\
\text { infeed }\end{array}$ & $0.5: 0.5$ & 500 & 1.238 & 0.538 \\
\cline { 3 - 5 } $\begin{array}{c}\text { Cascaded } \\
\text { converter }\end{array}$ & $0.5,0.25$, & 1000 & 2.364 & 0.544 \\
\cline { 3 - 5 } & 0.25 & 500 & 3.250 & 0.552 \\
\cline { 3 - 5 } & & 500 & 1.926 & 0.278 \\
\hline
\end{tabular}


This paper is a post-print of a paper accepted for publication in IEEE Journal of Emerging and Selected Topics in Power Electronics and is subject to Institution of Electrical and Electronic Engineering Copyright. The copy of record is available at IEEE Xplore Digital Library

As shown in Table 2, for the long distance HVDC system connected to a weak receiving system, the maximum infed power of the cascaded converter is 1.107 (total infeed power of grids 1 and 2), which is higher than that of the hierarchical connection mode (1.082) and the single infeed mode $(0.688$, 0.979).

\section{Control Strategies of THE HVDC System EMBEDDING CASCADED CONVERTER}

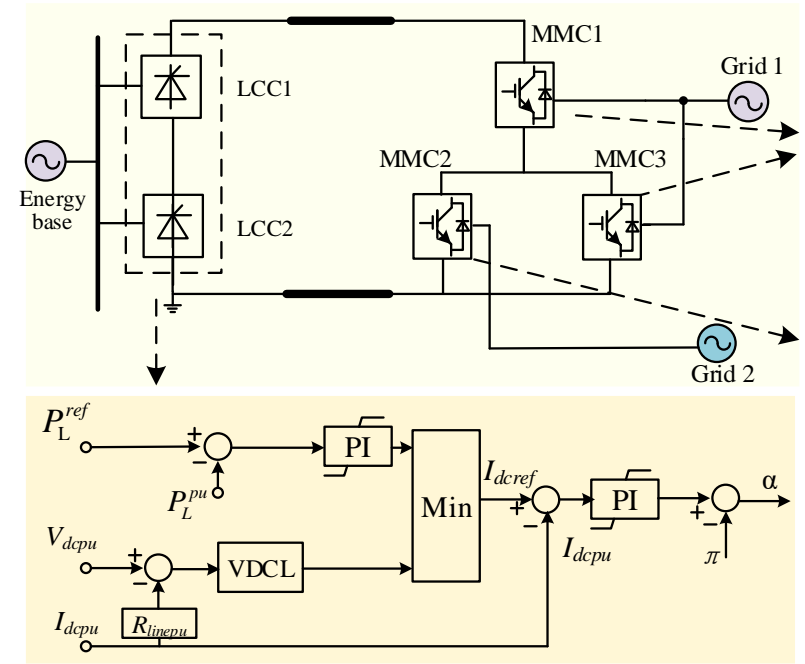

Fig. 5. Control strategy of cascaded converter valve.

\section{B. DC Fault Isolation Strategy}

When DC faults occur on the overhead line, the rectifier LCC can increase the firing angle to reduce the fault current. However, for the inverter, the AC grids will feed fault current even if the cascaded converter is blocked, as shown in Fig. 6(a). To block the fault current, the thyristors in the upper and lower valves of cascaded converter are used to block the current path during the DC fault, as shown in Fig. 6 (b).

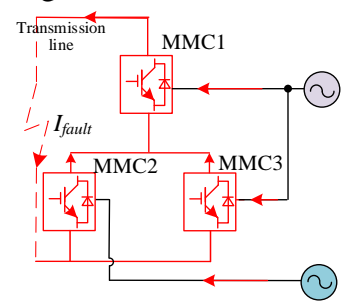

(a)DC fault current

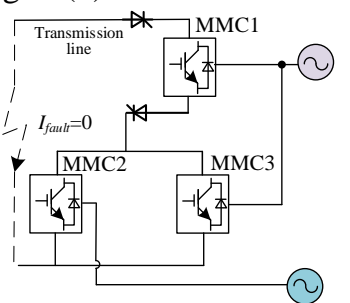

(b) Fault current through thyristors
Fig. 6. DC fault clearing strategy of cascaded converter.

Once a DC fault happens, the thyristors can block the fault current path thus preventing receiving grids feeding fault current to the DC lines. However, during the blocking of DC faults, the thyristors should withstand the whole DC link voltage. Thus, a number of thyristors are implemented in series. The total number of thyristors $n_{\mathrm{s}}$ can be determined by

$$
n_{s}=\frac{V_{d c N}}{V_{r r m}} k_{s}
$$

where $V_{d c N}$ is the rated DC link voltage; $V_{r r m}$ is the reversed withstand voltage of a single thyristor; $k_{s}$ is the redundancy factor. During steady-state operation, the thyristors remain on-state. Denote the on-state resistance of the thyristor is $r_{T}$, then the conduction losses of the thyristor group are:

\section{A. Control Strategy under Steady State}

The control scheme of cascaded converter based HVDC system is shown in Fig. 5. The rectifier LCC controls the DC current/power of the transmission system with a voltage-dependent current order limit control (VDCL). The MMC1 and MMC3 inside cascaded converter control the DC link voltages of the upper valve and lower valve respectively. MMC2 is used to control the power feeding into Grid 2.

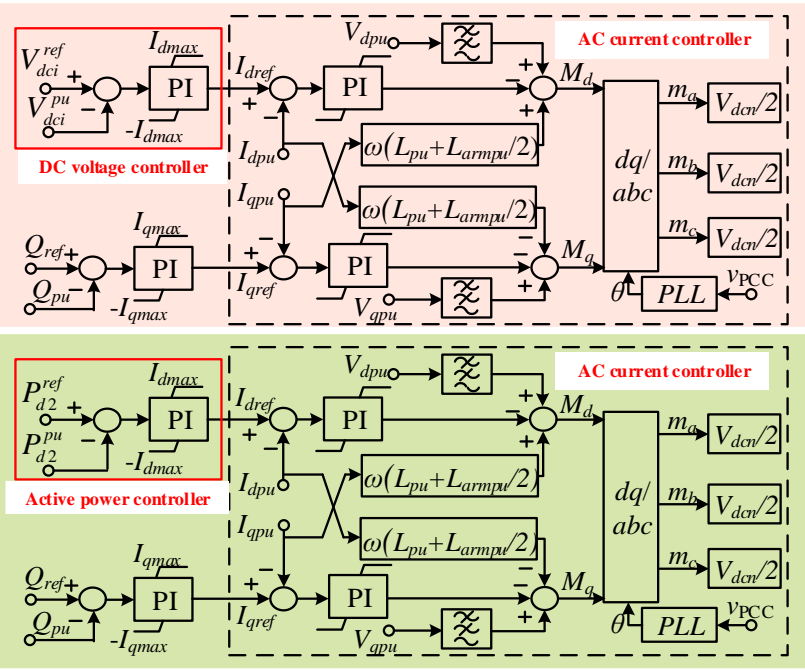

$$
P_{\text {Tloss }}=I_{d c}^{2} n_{s} r_{T}
$$

Taking the ABB thyristor 5STP $45 \mathrm{Y} 8500$ as an example, the on-state resistance is $0.16 \mathrm{~m} \Omega$ and the reverse withstand voltage is $8.5 \mathrm{kV}[20]$. Thus, the power loss ratio for an $800 \mathrm{kV} / 3000 \mathrm{MW}$ HVDC system is around $0.0075 \%$, far less than the loss of converter and the transmission line.

\section{V.OPERATING MOdes OF CASCADED CONVERTER}

The cascaded converter based HVDC system has multiple operating modes. Once a sub-converter quits operation or under maintenance, due to the capacity limitation of sub-converters, the transmitted power $P_{L}$ will be reduced. It can switch to another operating mode to guarantee a certain power transmission, which improves the flexibility of the system.

\section{A. Back-to-Back Asynchronous Interconnection Mode}

The cascaded converter will switch to back-to-back asynchronous interconnection mode in the following conditions.

\section{1) Upper-valve quits operation}

Denote the normal operating condition as mode I. When the upper valve MMC1 quits operation, the HVDC system operates at power infeed and asynchronous mode (mode II). Fig. 7 (a) shows the circuit of this mode. Since MMC1 is bypassed, the HVDC system operates at half the DC voltage. To obtain a stable operating point, $\mathrm{LCC} 1$ is also bypassed. The HVDC system remains half DC voltage and power transmission. The power directly feeds into two asynchronous grids.

\section{2) Sending terminal quits operation or DC line permanent fault}


When the sending terminal quits operation or a permanent DC line fault occur, the LCCs and MMC1 will be blocked and the high valve branch is isolated by the bypass breaker CB4. The HVDC system operates at asynchronous operation condition (mode III). Fig. 7 (b) shows the circuit of this mode. The HVDC system stops power transmission but the lower-valve maintains the asynchronous interconnection of the receiving grids.

\section{B. HVDC infeed with Hierarchical Connection Mode}

When MMC2 quits operation, cascaded converter can

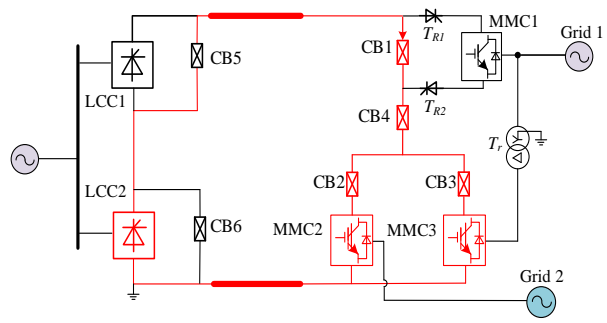

(a) Operating mode II

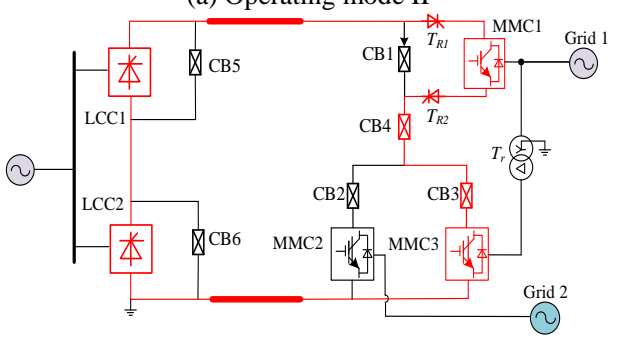

(c) Operating mode IV

Fig. 7. Multiple modes of cascaded converter.

\section{Online Switching Strategies between Operating Modes}

To smoothly switch between the operating modes, the switching strategies should be designed. Since mode II and mode III are similar and so as mode IV and mode V, the switching strategies from mode I to mode II and mode IV are considered.

\section{1) Switching strategy from mode I to mode II}

The switching strategy of cascaded converter from mode I to mode II is shown in Fig. 8. Firstly, the power references of

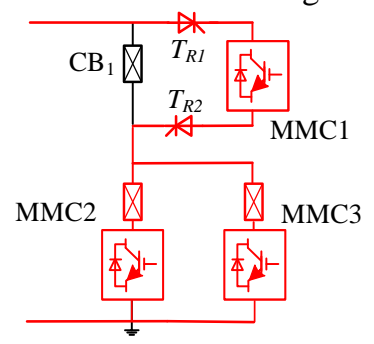

(a) Reduce the active power to 0

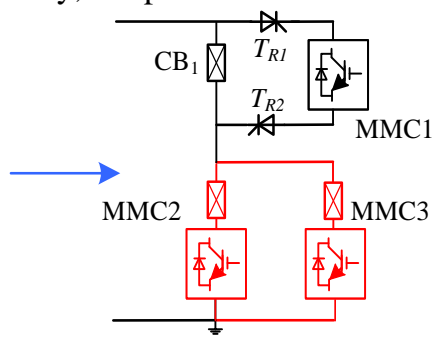

(b) Turn off thyristors $T_{R I}-T_{R 2}$
Fig. 8. Switching strategy from mode I to mode II.

2) Switching strategy from mode I to mode IV

The switching strategy of cascaded converter from mode I to mode IV is shown in Fig. 9. Firstly, the power reference of MMC2 is set to 0 . Meanwhile, due to the capacity limitation of MMC3, the power order of LCC is reduced to half of its rated switch to HVDC infeed with hierarchical connection mode (mode IV). As shown in Fig. 7 (c), the power delivered by HVDC feed into a synchronous grid with different AC voltages.

\section{HVDC Single Layer Infeed to Different Grids}

When MMC3 quits operation, the power can be transmitted to two asynchronous grids (mode V). Fig. 7 (d) shows the circuit of this mode. The DC power is fed into Grid 1 and Grid 2 through MMC1 and MMC2 respectively.

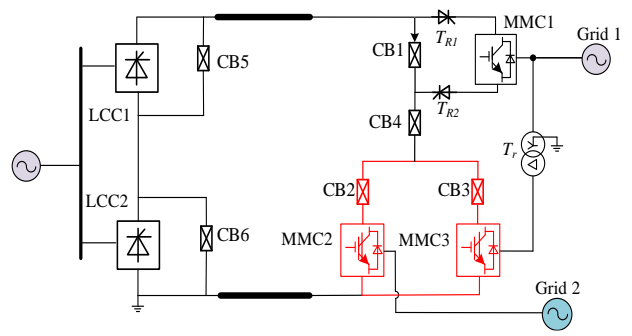

(b) Operating mode III

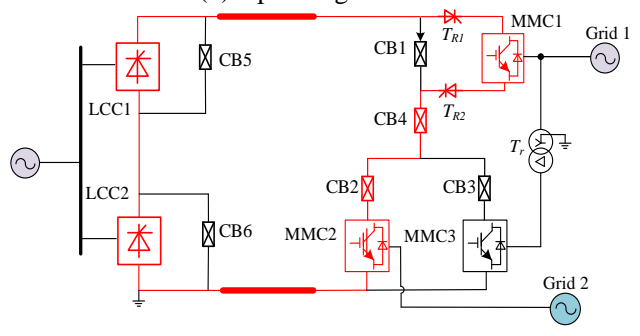

(d) Operating modeV

LCC and MMC2 are decreased to 0 . When the currents flowing through the sub-converters drop to zero, thyristors $T_{R I}$ and $T_{R 2}$ will be turned off to isolate the rectifier and inverter terminals. Then, LCCs shifts to DC voltage control to reduce the DC voltage of the HVDC system to half of the rated value. Then, bypass breaker CB1 is turned on to bypass MMC1. Meanwhile, MMC 1 is blocked. Afterwards, LCC shifts to current control, and the power order of MMC2 resumes. The HVDC system finally switches to operating mode II.

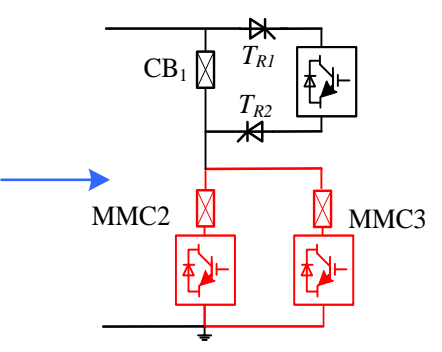

(c) Reduce Voltage of LCC, block MMC1

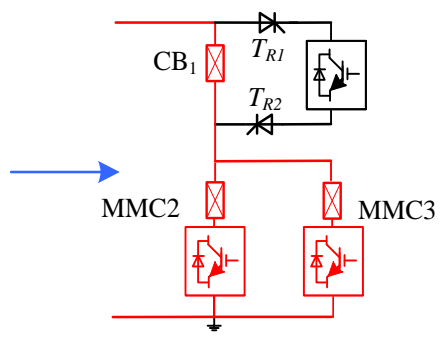

(d) Turn on CB1 value. When the current flowing into MMC2 is lower than the breaking-current of $\mathrm{CB} 2$, the breaker is turned off to isolate the sub-converter from the system. Then, MMC2 will be blocked. The cascaded converter will be switched to mode IV. 


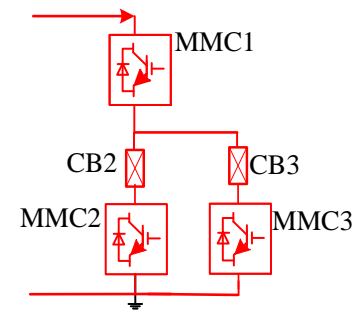

(a)Reduce the active power of MMC3

Fig. 9. Switching strategy from mode I to mode IV.

\section{EXTENDED TOPOLOGIES OF CASCADED CONVERTER}

To meet different application requirements, the cascaded converter can be extended to other topologies.

\section{A. Hybrid UHVDC Inverter}

Since the voltage and power ratings of LCC is larger than that of the MMC, an alternative way is to use LCC converter as the upper valve and use multiple MMCs as the lower valve to feed different power grids. The topology of this hybrid inverter is shown in Fig. 10. As MMCs are able to provide reactive power compensation, the immune to commutation failure of LCC inverter can be improved. This topology also has the ability to block DC fault currents. Compared with the cascaded converter in this paper, the hybrid inverter can further reduce the cost.

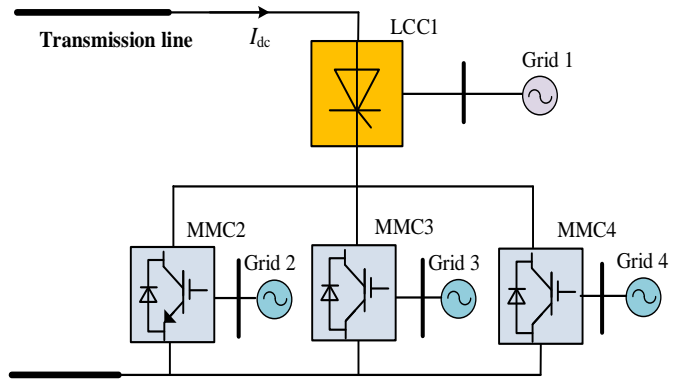

Fig. 10. UHVDC hybrid inverter based on LCC and half-bridge MMC.

The hybrid MMC based on half-bridge sub-module (SM) and full-bridge SM can also be adopted to realize DC fault ride through [7], as shown in Fig. 11. In Fig. 11, each arm of hybrid MMC is consisted of half half-bridge sub-modules and half full-bridge sub-modules. Thus, four types of inverter topologies can be obtained as shown in Fig. 12. Type 1 represents the cascaded inverter based on half bridge MMC and thyristors. Type 2 represents the cascaded inverter based on LCC and half-bridge MMC as proposed in Fig. 10. Type 3 represents the cascaded inverter based on LCC and hybrid MMC. Type 4 represents the cascaded inverter based on hybrid MMC.

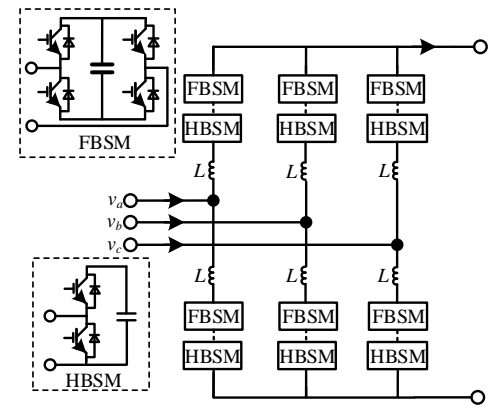

Fig. 11. Topology of hybrid MMC.

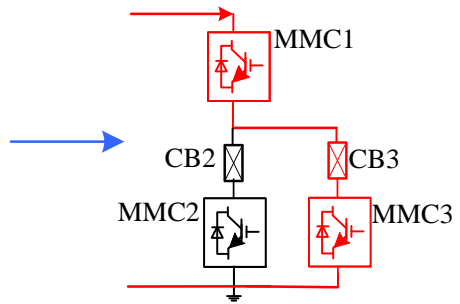

(c) Block MMC2

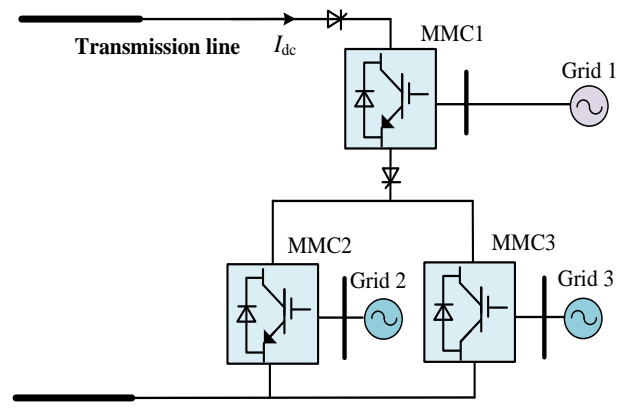

(a) Type 1 (MMC and thyristor)

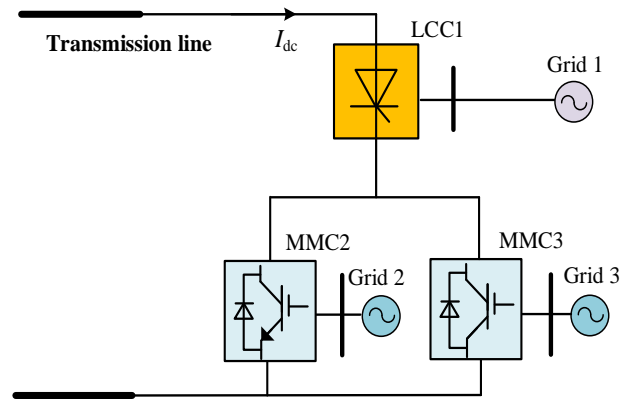

(b) Type 2 (LCC and MMC)

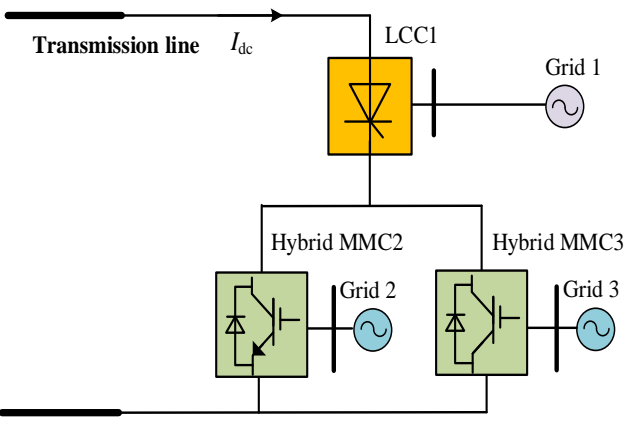

(c) Type 3 (LCC and hybrid MMC)

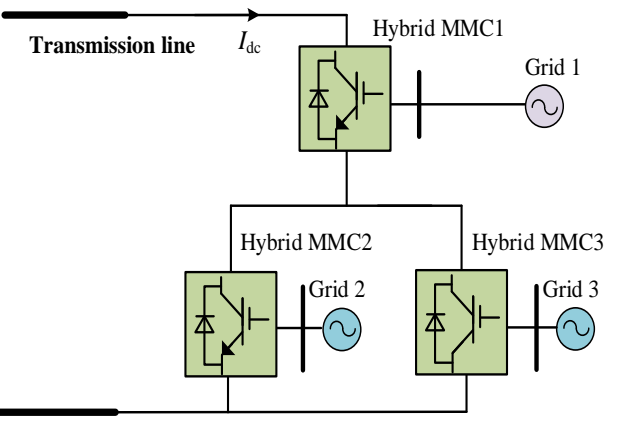

(d) Type 4 (hybrid MMC)

Fig. 12. Several inverter topologies.

Since the sub-converters are constructed in one station, thus, only the HVDC transmission line faults are considered. For type 1 converter, the DC fault current can be blocked by 
turning off the thyristors. For type 2 and 3 converters, the DC fault current can be cut off by blocking LCC. For type 3 and 4 converters, by adopting the DC fault current limiting control as disclosed in [7], the hybrid MMCs can ride through the DC faults with providing reactive power support.

As shown in Fig. 12, since LCC is adopted, type 2 and 3 converters will suffer from commutation failure once there are serious AC faults happening at Grid 1. And the cascaded converter can transmit half the rated active power under half the rated DC voltage. For type 1 and 4 converters, there is no commutation failure problem.

As can be seen, the hybrid MMC contains more power electronic devices compared with half-bridge MMC and LCC. Thus, the conduction power loss and cost of type 4 converter are highest among these four converters. According to [21]-[23], the operating power loss of LCC, half-bridge MMC and hybrid MMC are around $0.34 \%, 0.6 \%$ and $0.8 \%$ of the rated power respectively. Therefore, supposing the rated capacity of cascaded converters are the same and the capacity proportion of upper sub-converter and lower converters is 1 : $0.5: 0.5$, the operating power loss of these cascaded converters can be approximately as:

Type 1 (half-bridge $\mathrm{MMC}$ and thyristors):

$P_{\text {loss } 1}=(0.6 \% \times 1+0.6 \% \times 0.5+0.6 \% \times 0.5) /(1+0.5+0.5)=0.6 \%$

(neglecting the conduction power loss of thyristors);

Type 2 (half-bridge MMC and LCC):

$P_{\text {loss } 2}=(0.34 \% \times 1+0.6 \% \times 0.5+0.6 \% \times 0.5) /(1+0.5+0.5)=0.47 \%$;

Type 3 (hybrid MMC and LCC):

$P_{\text {loss } 3}=(0.34 \% \times 1+0.8 \% \times 0.5+0.8 \% \times 0.5) /(1+0.5+0.5)=0.57 \%$;

Type 4 (hybrid MMC):

$P_{\text {loss } 4}=(0.8 \% \times 1+0.8 \% \times 0.5+0.8 \% \times 0.5) /(1+0.5+0.5)=0.8 \%$.

To be concluded, the comparisons of the four types of cascaded converters are listed in Table 3.

Table 3 Overall compassions of different topologies of cascaded converters.

\begin{tabular}{c|c|c|c|c}
\hline $\begin{array}{c}\text { Technical } \\
\text { features }\end{array}$ & Type 1 & Type 2 & Type 3 & Type 4 \\
\hline $\begin{array}{c}\text { DC fault blocking } \\
\text { capability }\end{array}$ & Yes & Yes & Yes & Yes \\
\hline $\begin{array}{c}\text { DC fault ride } \\
\text { through }\end{array}$ & No & No & Yes & Yes \\
\hline $\begin{array}{c}\text { commutation } \\
\text { failure }\end{array}$ & No & Yes & Yes & No \\
\hline $\begin{array}{c}\text { Operating power } \\
\text { loss }\end{array}$ & $0.6 \%$ & $0.47 \%$ & $0.57 \%$ & $0.8 \%$ \\
\hline Cost & medium & lowest & medium & highest \\
\hline
\end{tabular}

\section{B. UHVDC Rectifier Integrating Wind Farms of Different Voltage and Power Ratings}

The cascaded converter can also be applied to the rectifier side. Fig. 13 shows a cascaded rectifier integrating multiple wind farms. As we know, the output power and voltage vary with the different size of wind farms. A high turns-ratio AC transformer is required for the integration of small-scale wind farms. However, in Fig. 13, the large-scale wind farm is directly connected to MMC 1 and LCC. While several small-scale wind farms are directly connected to MMC 2 and MMC 3, which are paralleled with MMC 1. Thus, the interface transformers are avoided and the rectifier enables black-start and self-commutation.

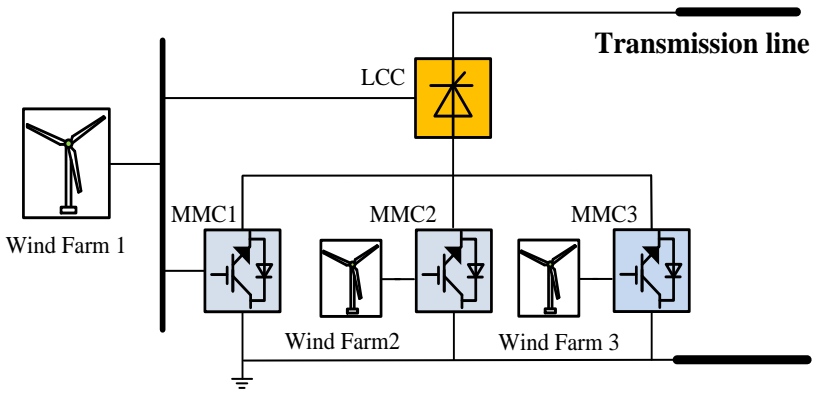

Fig. 13. Rectified cascaded converter.

\section{SimUlation VERIFICATIONS}

To verify the effectiveness of the proposed cascaded converter, a HVDC system based on cascaded converter shown in Fig. 1 is built in PSCAD/EMTDC. The parameters of the test system are listed in Table 4 and Table 5. During normal operation, MMC1 controls the DC voltage $V_{d c l}$ and outputs 450 Mvar reactive power, MMC3 controls the DC voltage $V_{d c 2}$ and outputs 250 Mvar reactive power, MMC2 controls the active power $P_{d 3}$ and outputs 300 Mvar reactive power.

Table 4 Parameters of the hybrid HVDC transmission system.

\begin{tabular}{c|c|c|c|c}
\hline Parameters & LCC & MMC1 & MMC2 & MMC3 \\
\hline $\begin{array}{c}\text { Rated } \\
\text { capacity/MVA }\end{array}$ & 3000 & 1500 & 750 & 750 \\
\hline $\begin{array}{c}\text { Rated DC } \\
\text { voltage/kV }\end{array}$ & 800 & 400 & 400 & 400 \\
\hline $\begin{array}{c}\text { DC inductance } \\
/ \mathrm{mH}\end{array}$ & 300 & 100 & 100 & 100 \\
\hline $\begin{array}{c}\text { Arm } \\
\text { inductance/mH }\end{array}$ & $/$ & 12 & 18 & 18 \\
\hline $\begin{array}{c}\text { Rated AC } \\
\text { voltage/kV }\end{array}$ & 1000 & 1000 & 500 & 500 \\
\hline Number of SM & $/$ & 190 & 190 & 190 \\
\hline $\begin{array}{c}\text { Capacitor of } \\
\text { SM/mF }\end{array}$ & $/$ & 25 & 15 & 15 \\
\hline
\end{tabular}

Table 5 Parameters of the AC systems.

\begin{tabular}{c|c|c|c}
\hline Parameters & AC Grid 1 & AC Grid 1 & AC grid 2 \\
\hline $\begin{array}{c}\text { Rated line to line AC } \\
\text { voltage/kV }\end{array}$ & 1000 & 500 & 500 \\
\hline Frequency/Hz & 50 & 50 & 50 \\
\hline Base capacity/MW & 1500 & 750 & 750 \\
\hline Short circuit ratio (SCR) & 3 & 2 & 2 \\
\hline AC system X/R ratio & 10 & 8 & 8 \\
\hline AC transformer $T_{r}$ & $\begin{array}{c}1000 \mathrm{kV} / 500 \mathrm{kV}, \text { leakage } \\
\text { reactance } 0.15 \mathrm{pu}\end{array}$ & $/$ \\
\hline $\begin{array}{c}\text { Interconnection impedance } \\
\text { between Grid 1 and Grid 1 }\end{array}$ & \multicolumn{2}{|c}{$0.9 \mathrm{pu}$} \\
\hline
\end{tabular}

\section{A. Response to Power Order Change}

To test the performance of the proposed cascaded converter under change of operating conditions, the active power order of LCC drops from 1pu to 0.8pu at $1.5 \mathrm{~s}$ and increases from $0.8 \mathrm{pu}$ to $1 \mathrm{pu}$ at $3.5 \mathrm{~s}$. While the active power order of MMC2 reduces from $1 \mathrm{pu}$ to $0.6 \mathrm{pu}$ at $2 \mathrm{~s}$ and increases from $0.6 \mathrm{pu}$ to $1 \mathrm{pu}$ at $3 \mathrm{~s}$. The simulation results are shown in Fig. 14.

Fig. 14 (a) shows the active power of LCC and sub-converters of the cascaded converter. As can be seen, when the transmitted power is reduced to $2400 \mathrm{MW}$, the output power of MMC 1 and MMC3 reduces 300MW respectively. After 2.2s, the output power of MMC2 reduces to $450 \mathrm{MW}$, while MMC1 and MMC3 output 1200MW and $750 \mathrm{MW}$ 
This paper is a post-print of a paper accepted for publication in IEEE Journal of Emerging and Selected Topics in Power Electronics and is subject to Institution of Electrical and Electronic Engineering Copyright. The copy of record is available at IEEE Xplore Digital Library

active power respectively. After $3.7 \mathrm{~s}$, each converter resumes rated operation. Fig. 14 (b) shows the DC link voltage of the HVDC system, the high and low valves. They operate at the rated value during the change of operating conditions. Fig. 14 (c)-(d) show the capacitor voltages and arm currents of MMC1

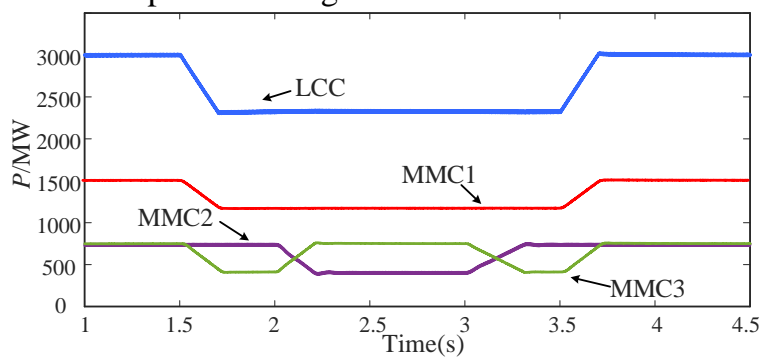

(a) Active power of HVDC system

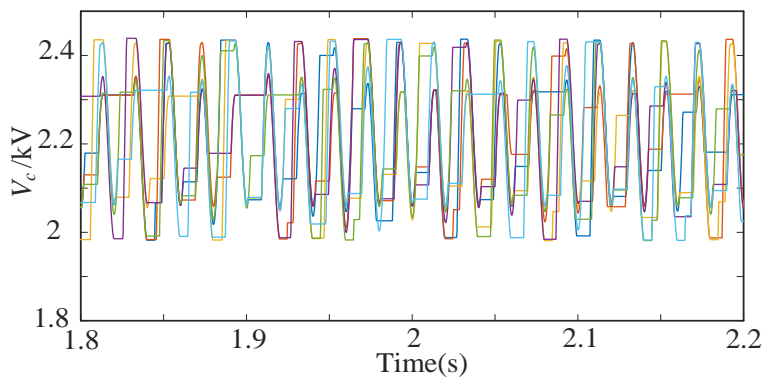

(c) Capacitor voltages of the upper arm of phased A of MMC1

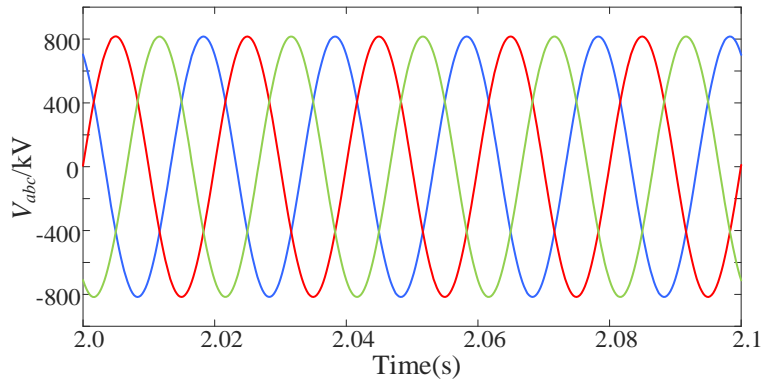

(e) Grid AC voltages at MMC1

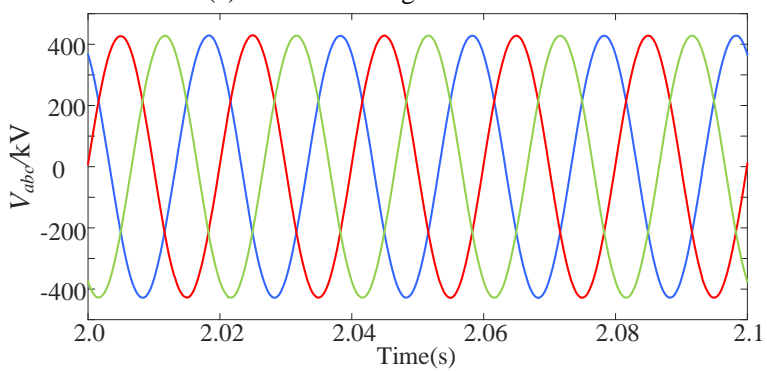

(g) Grid AC voltages at MMC3

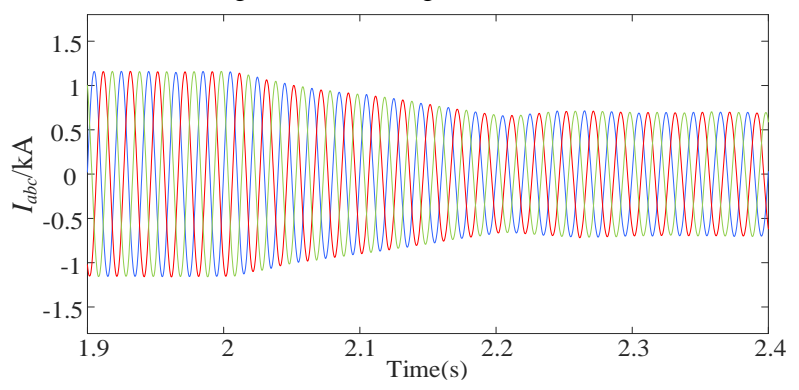

(i) Grid AC currents at MMC2

Fig. 14. Simulation results under change of operating conditions.

\section{B. Validation of DC Fault Clearance}

and MMC2 respectively. Fig. 14 (e)-(g) show the grid voltages at MMC side while Fig. 14 (h)-(j) show the grid currents. The dynamics show that the sub-converters are well operated during change of operating conditions.

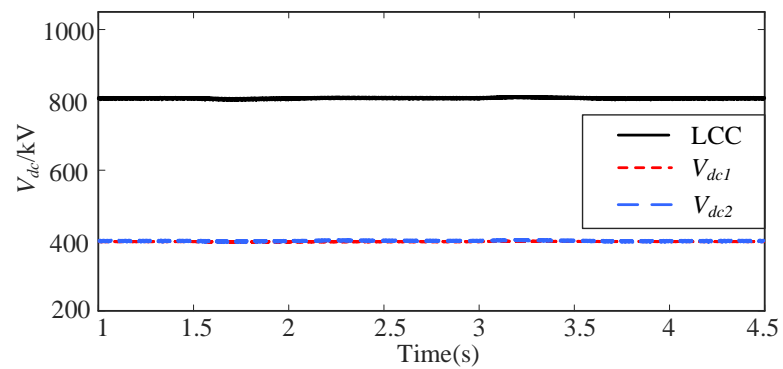

(b) DC voltages of HVDC system

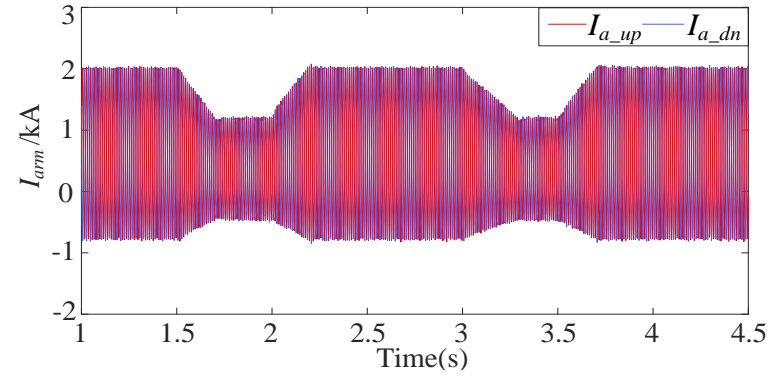

(d) Arm currents of phased A of MMC2

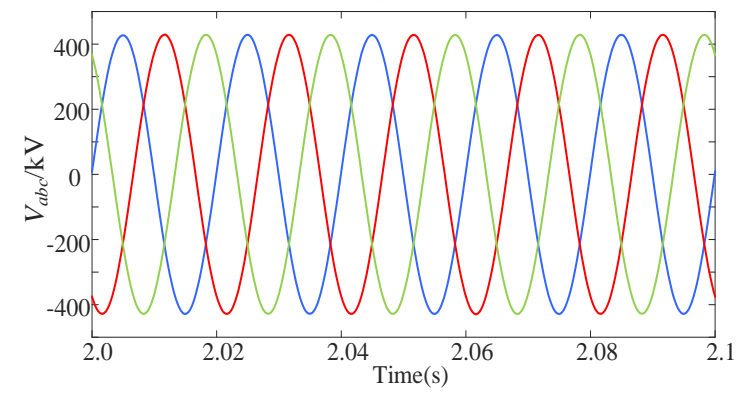

(f) Grid AC voltages at MMC2

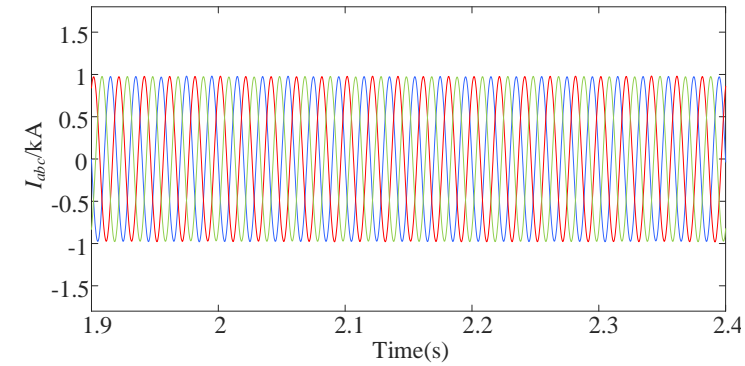

(h) Grid AC currents at MMC1

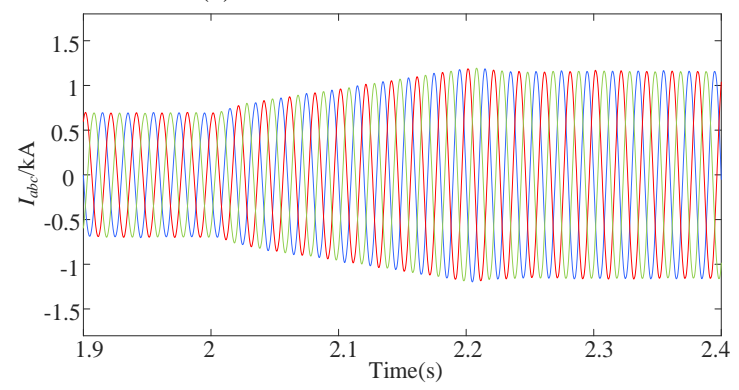

(j) Grid AC currents at MMC3

At $1.5 \mathrm{~s}$, the HVDC line is subjected to a temporary pole-to-ground fault lasting for $0.2 \mathrm{~s}$. The simulation results are 
shown in Fig. 15.

Fig. 15 (a) shows the DC link voltages $\left(V_{d c l}, V_{d c 2}, V_{d c 0}\right)$. Once the fault is detected, LCC will increase the firing angle to 150 to extinguish the fault arc. When the DC current reduces to zero, $T_{R 1}-T_{R 2}$ are turned off. The fault current path will be isolated, as shown in Fig. 15 (b) and (c). Fig. 15 (d) shows the voltage across $T_{R 1}-T_{R 2}$. As can be seen, the thyristors withstand the DC voltage as high as $400 \mathrm{kV}$ during fault isolation. Fig. 15 (e) shows the reactive power of sub-converters. As can be seen, they operate as STATCOMs to support the AC systems. Fig. 15 (f)-(i) show that the capacitor voltages and arm currents are within the safe range during the fault. When the fault is self-cleared, the HVDC system restores normal operation within $200 \mathrm{~ms}$.

\section{Simulation of operating mode switching}

\section{1) Switching strategy from mode I to mode II}

Supposing a permanent three-phase short circuit fault with $0.3 \Omega$ fault resistance occurs at $F_{a c}$ at $1 \mathrm{~s}$ as depicted in Fig. 1. Due to the AC fault, the DC power cannot be transmitted into Grid 1. Thus, the system will switch to mode II operation. Fig. 16 shows the switching process. Fig. 16 (a) shows the DC currents of LCC and MMCs. At 1.05s, the power orders of

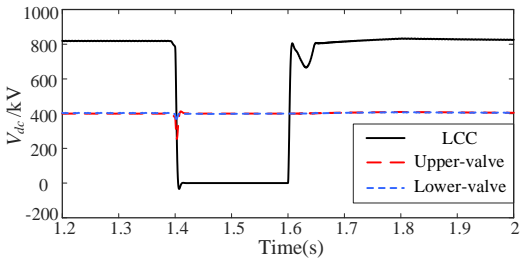

(a) Voltages of HVDC system

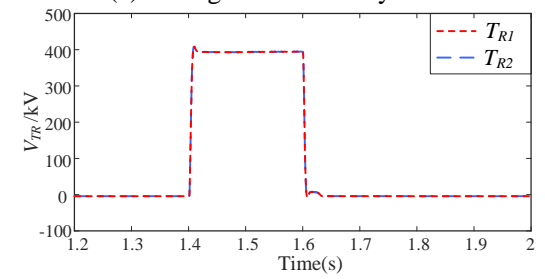

(d) Voltages across $T_{R 1}-T_{R 2}$

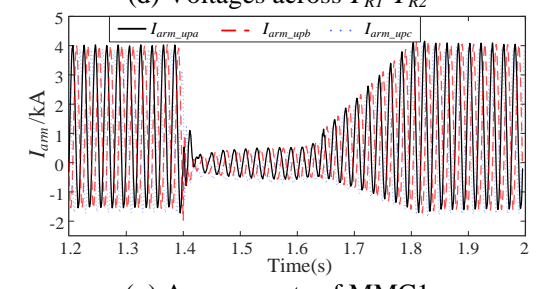

(g) Arm currents of MMC1

Fig. 15. Simulations for DC fault clearing and restarting.

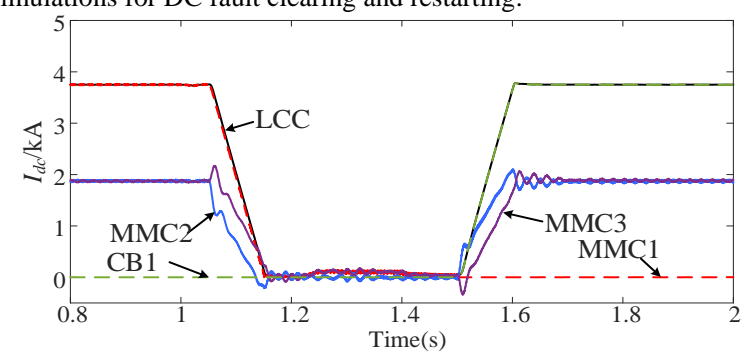

(a) DC currents of HVDC system
LCC and MMC2 are decreased to zero. As can be seen, the currents are controlled to zero after a short transient. Then, TR1 and TR2 are turned off to isolate MMC 1. Meanwhile, LCC shifts to DC voltage control and its DC voltage drops to half of the rated voltage. The voltage of the lower-valve remains unchanged. When the DC link voltage is established, the bypass breaker CB1 is turned on to bypass MMC1. Then, LCC is shifted back to active power control and the active power command increases to half of the rated active power. The DC link voltages are shown in Fig. 16 (b). As can be seen, the DC voltage of LCC drops to $400 \mathrm{kV}$ at $1.6 \mathrm{~s}$. Since the DC current is zero, no transients are observed. Then, the power orders of LCC and MMC2 restores. The HVDC system operates at half DC voltage and half active power transmission, as shown in Fig. 16 (c). During the whole process, the bypass breakers operate only at zero current. Fig. 16 (d) shows the arm currents of phase A of MMC1. As can be seen, the overcurrent is still within the safe range (less than twice times of the rated value). Fig. 16 (e)-(f) shows the grid voltages and currents at the converter side. Since the electrical distance between Grid 1' and Grid 1 is far, the AC fault in Grid 1 will not affect MMC3, as shown in Fig. 16 (i) and Fig. 16 (j).

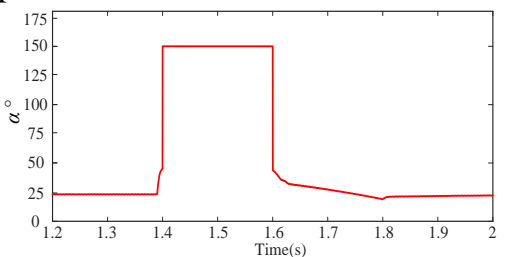

(b) Firing angle of LCC

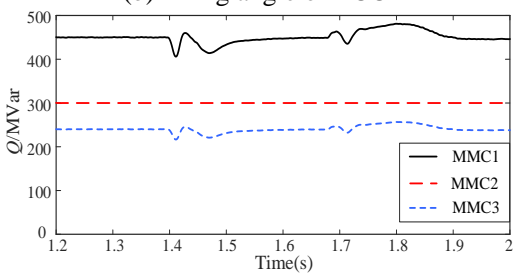

(e) Reactive power of sub-converters

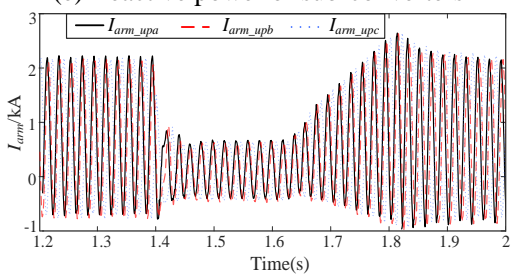

(h) Arm currents of MMC2

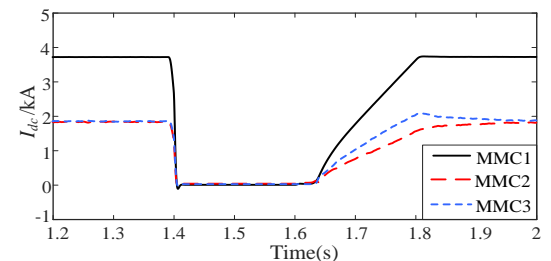

(c) DC currents of the HVDC system

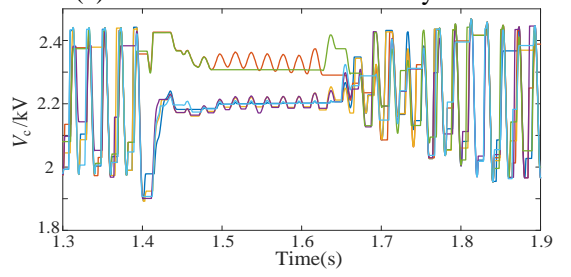

(f) Capacitor voltages of MMC1

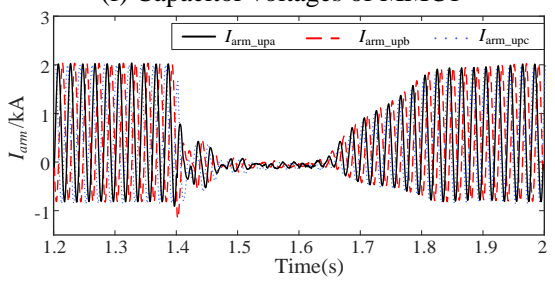

(i) Arm currents of MMC3

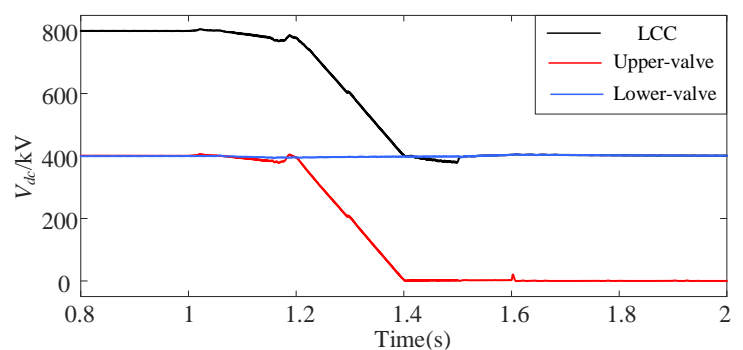

(b) DC voltages of HVDC system 
This paper is a post-print of a paper accepted for publication in IEEE Journal of Emerging and Selected Topics in Power Electronics and is subject to Institution of Electrical and Electronic Engineering Copyright. The copy of record is available at IEEE Xplore Digital Library

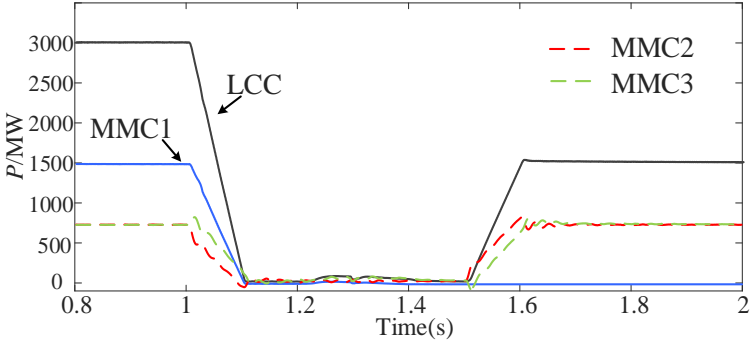

(c) Active power of HVDC system

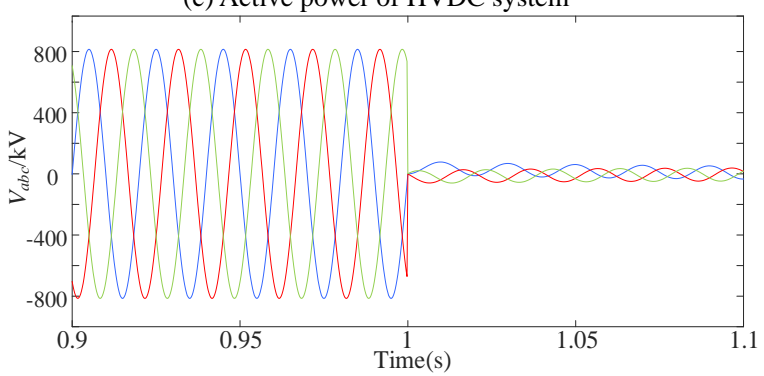

(e) Grid AC voltages at MMC1

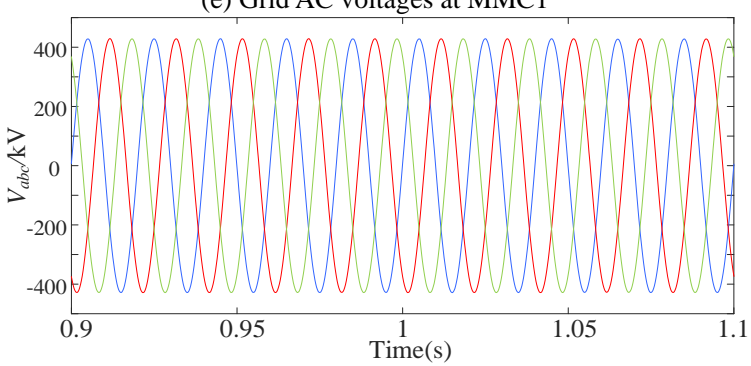

(g) Grid AC voltages at MMC2

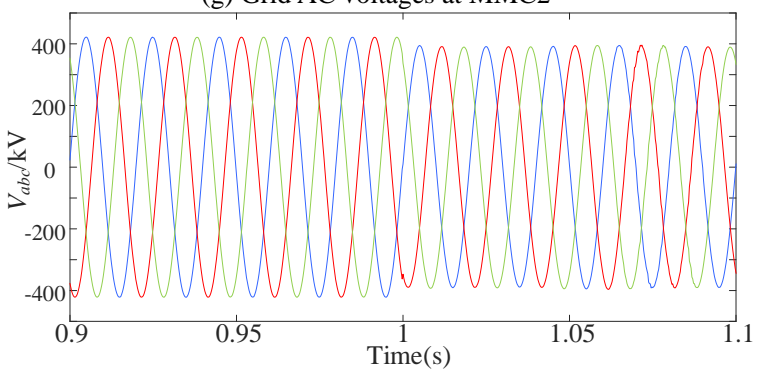

(i) Grid AC voltages at MMC3

Fig. 16. Simulations of operating modes switching (mode I to II).

2) Switching strategy from mode I to mode IV

Fig. 17 shows the switching process from mode I to mode IV. Fig. 17 (a) shows the DC currents of LCC and MMCs. At $1.5 \mathrm{~s}$, the DC current of MMC2 is controlled to 0 and the DC current of LCC is controlled to $0.5 \mathrm{pu}$. Then, the bypass

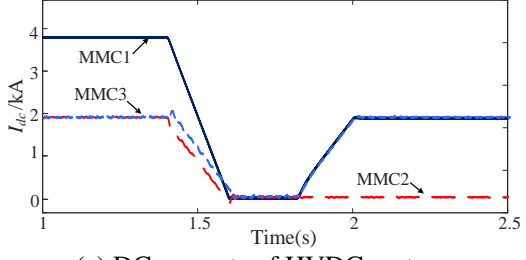

(a) DC currents of HVDC system

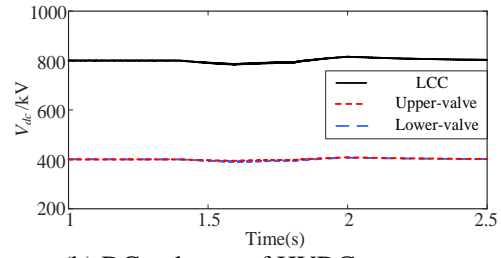

(b) DC voltages of HVDC systems

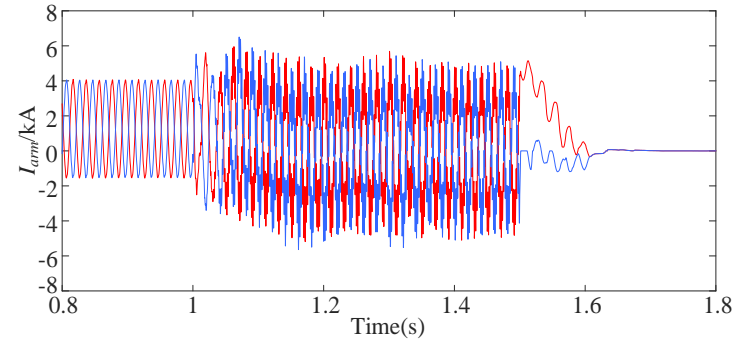

(d) Arm currents of phased A of MMC1

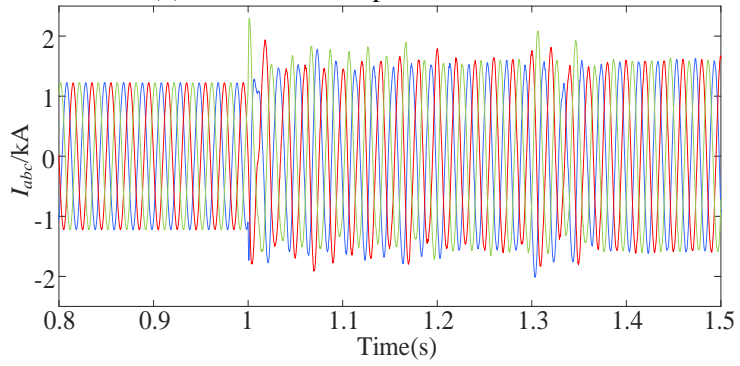

(f) Grid AC currents at MMC1

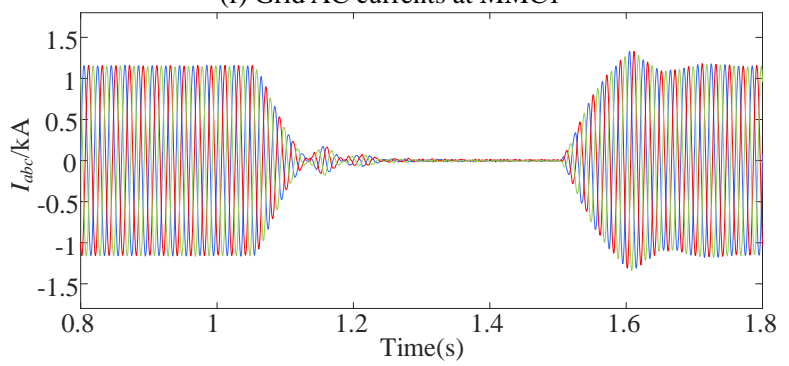

(h) Grid AC currents at MMC2

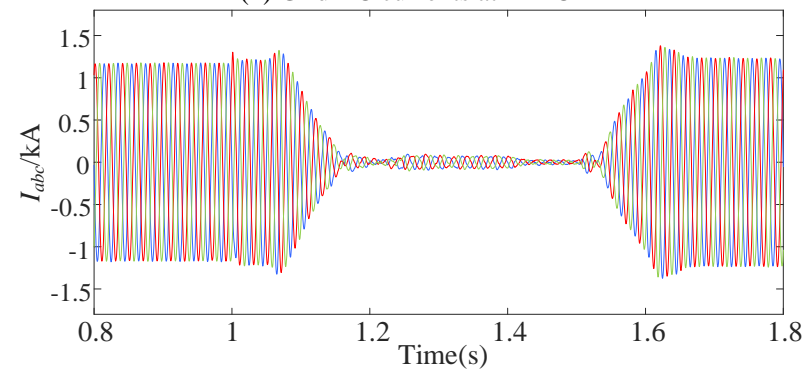

(j) Grid AC currents at MMC3

breaker $\mathrm{CB} 2$ is turned off to isolate MMC2. During the switching process, the DC link voltages are well controlled by MMC 1 and MMC3, as shown in Fig. 17 (b). After 1.8s, the HVDC system steadily operates at rated DC voltage but half active power transmission, as shown in Fig. 17 (c).

Fig. 17. Simulations of operating modes switching (mode I to IV).

\section{VIII.CONCLUSION}

A cascaded converter combining the merits of hierarchical infeed and back-to-back interconnection is proposed in this paper. The cascaded converter achieves high voltage and power infeed to receiving grids. The multi-infeed short circuit ratio of adopting cascaded converter is much larger compared with the single infeed and hierarchical infeed approaches, leading to reduction of short circuit currents. The power flow in the receiving grids can be optimized by the active power control of the cascaded converter. The cascaded converter enables multiple operating modes for the HVDC systems. Thus, the system is able to continuously transmit power when the sub-converter quits operation or under maintenance. The 
operational flexibility is improved. The thyristors group is able to cut off the DC fault current during DC faults. The simulation results show that the cascaded converter has a good application prospect in the large capacity UHVDC system connecting to developed load centers.

\section{REFERENCES}

[1] M. Langwasser, G. De Carne, M. Liserre and M. Biskoping, "Fault Current Estimation in Multi-Terminal HVDC Grids Considering MMC Control," IEEE Trans. Power Syst., early access, doi: 10.1109/TPWRS.2018.2887166

[2] T. Keim and A. Bindra, "Recent Advances in HVDC and UHVDC Transmission," IEEE Power Electron. Magazine, vol. 4, no. 4, pp. 12-18, Dec. 2017.

[3] F. Zhang, H. Xin, D. Wu, Z. Wang and D. Gan, "Assessing Strength of Multi-infeed LCC-HVDC Systems Using Generalized Short Circuit Ratio," IEEE Trans. Power Syst., early access, doi: 10.1109/TPWRS. 2018.2868958

[4] Z. Zhang, Z. Xu, Y. Xue and G. Tang, "DC-Side Harmonic Currents Calculation and DC-Loop Resonance Analysis for an LCC-MMC Hybrid HVDC Transmission System," IEEE Trans. Power Del, vol. 30, no. 2, pp. 642-651, April 2015.

[5] G. Tang, Z. Xu, "A LCC and MMC hybrid HVDC topology with DC line fault clearance capability," International Journal of Electrical Power \& Energy Systems, vol.62, pp. 419-428, 2014.

[6] J. Jung, S. Cui, J. Lee and S. Sul, "A New Topology of Multilevel VSC Converter for a Hybrid HVDC Transmission System," IEEE Trans. on Power Electron., vol. 32, no. 6, pp. 4199-4209, June 2017.

[7] W. Xiang, W. Lin, L. Xu, J. Wen, "Enhanced Independent Pole Control of Hybrid MMC-HVDC System," IEEE Trans. Power Del., vol. 33, no. 2, pp. 861-872, Apr. 2018.

[8] Y. Liu, Z. Chen, "A Flexible Power Control Method of VSC-HVDC Link for the Enhancement of Effective Short-Circuit Ratio in a Hybrid Multi-Infeed HVDC System," IEEE Trans. Power Syst., vol. 28, no. 2, pp. 1568-1581, May 2013.

[9] N. Mohamed Haleem, A. D. Rajapakse, A. M. Gole and I. T. Fernando, "Investigation of Fault Ride-Through Capability of Hybrid VSC-LCC Multi-Terminal HVDC Transmission Systems," IEEE Trans. Power Del. early access, doi: 10.1109/TPWRD.2018.2868467.

[10] C. Guo, Y. Zhang, A. M. Gole, C. Zhao, "Analysis of Dual-Infeed HVDC with LCC-HVDC and VSC-HVDC," IEEE Trans. Power Del., vol. 27, no. 3, pp. 1529-1537, July 2012

[11] W. Lin, J. Wen, M. Yao, S. Wang, S. Cheng and N. Li, "Series VSC-LCC converter with self-commutating and dc fault blocking capabilities," 2014 IEEE PES General Meeting, National Harbor, MD, 2014, pp. 1-5.

[12] B. Zhou, H. Rao, W. Wu, et al, "Principle and Application of Asynchronous Operation of China Southern Power Grid," IEEE Journal of Emerging and Selected Topics in Power Electron., vol. 6, no. 3, pp. 1032-1040, Sept. 2018.

[13] W. Huang, Y. Lu, X. Li, et al, "A calculation method for maximum steady-state loss of VSC-HVDC grounding resistor in Luxi back-back HVDC interconnector," 12th IET International Conf. on AC and DC Power Transm. (ACDC 2016), Beijing, 2016, pp. 1-5.

[14] D. Cai, K. Zhou, W. Wang, et al, "Influence of back-to-back VSC-HVDC project on the operation characteristics of Hubei power grid," The Journal of Engineering, vol. 2017, no. 13, pp. 801-805, 2017.

[15] Y. Wen, C. Y. Chung, X. Ye, "Enhancing Frequency Stability of Asynchronous Grids Interconnected with HVDC Links," IEEE Transactions on Power Syst., vol. 33, no. 2, pp. 1800-1810, March 2018.

[16] Z. Liu, X. Qin, L. Zhao, et al, "Study on the application of UHVDC hierarchical connection mode to multi-infeed HVDC system," Proc. CSEE, vol. 33, no. 10, pp. 1-7, 2013.

[17] S. Li, Z. Wu and J. Huang, "Power flow modelling to UHVDC line and its hierarchical connection mode," IET Gener., Transm. \& Distri., vol. 12, no. 7, pp. 1554-1564, Mar. 2018.

[18] CIGRE Working Group B4.41, "Systems with multiple DC infeed," CIGRE, 2008.

[19] P. C. S. Krishayya, R. Adapa, M. Holm et al, "IEEE guide for planning DC links terminating at AC locations having low short-circuit capacities, Part I: AC/DC system interaction phenomena," CIGRE, 1997.

[20] ABB. Phase Control Thyristor: 5STP 45Y8500 Data Sheet. Lenzburg, Switzerland: ABB Switzerland Ltd., [02-10-2016]. https:// new.abb.com/ semiconductors/thyristors/phase-controlled-pct.

[21] D. Jovcic, K. Ahmed, "High-Voltage Direct-Current Transmission: Converters, Systems and DC Grids," John Wiley \& Sons, Ltd, 2015.

[22] R. Zeng, L. Xu, L. Yao, et al, "Design and Operation of a Hybrid Modular Multilevel Converter," IEEE Trans. Power Electron., vol. 30, no. 3, pp. 1137-1146, March 2015.

[23] J. Qin, M. Saeedifard, A. Rockhill, et al, "Hybrid Design of Modular Multilevel Converters for HVDC Systems Based on Various Submodule Circuits," IEEE Trans Power Del., vol. 30, no. 1, pp. 385-394, Feb. 2015 .

\section{BIOGRAPHIES}

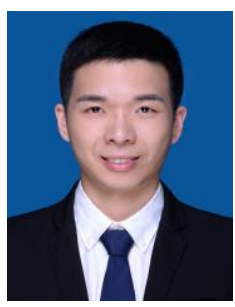

Wang Xiang (S'16-M'17) received his B.Eng. and $\mathrm{PhD}$ degrees both in electrical engineering from Huazhong University of Science and Technology (HUST), China in 2012 and 2017 respectively. He was a visiting student at the University of Aberdeen and the University of Strathclyde in 2014 and 2016 respectively. Currently, he is a research fellow at HUST. His main research interests include MMC-HVDC, high power dc/dc converters and dc grids.

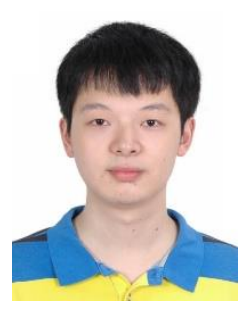

Ruizhang Yang received his B.Eng. degree in electrical engineering from Huazhong University of Science and Technology (HUST), China, in 2017. Currently, he is pursuing his M.S. degree at HUST. His research interests include MMC-HVDC, hybrid HVDC systems as well as its control \& protection.

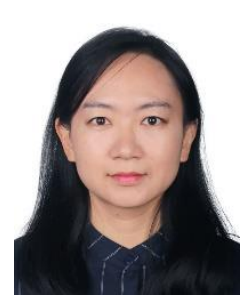

Chang Lin received both her bachelor and master degrees in Electrical Engineering \& its Automation from North China Electric Power University (Beijing, China) in 2006 and 2009, respectively. Currently, she is a senior research engineer in DC Grid Simulation Department of Global Energy Interconnection Research Institute Co. Ltd. Her research interests include the modelling, simulation study of the Voltage-sourced Converter HVDC system, as well as its control \& protection studies.

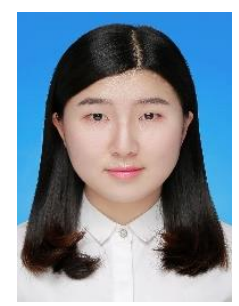

Jiapei Zhou received the bachelor degree in Electrical Engineering \& its automation from Taiyuan University of Technology, China, in 2015 and the master degree in Power System \& its automation from North China Electric Power University, China, in 2018. Currently, she is a research engineer in DC Grid Simulation Department of Global Energy Interconnection Research Institute Co. Ltd. Her research interests include MMC-HVDC and DC grid.

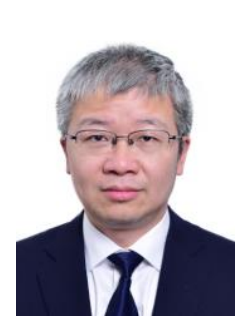

Jinyu Wen (M'10) received his B.Eng. and Ph.D. degrees all in electrical engineering from Huazhong University of Science and Technology (HUST), Wuhan, China, in 1992 and 1998, respectively. He was a visiting student from 1996 to 1997 and research fellow from 2002 to 2003 all at the University of Liverpool, $\mathrm{UK}$, and a senior visiting researcher at the University of Texas at Arlington, USA in 2010. From 1998 to 2002 he was a director engineer in XJ Electric Co. Ltd. in China. In 2003 he joined the HUST and now is a Professor at HUST. His current research interests include renewable energy integration, energy storage application, DC grid, and power system operation and control.

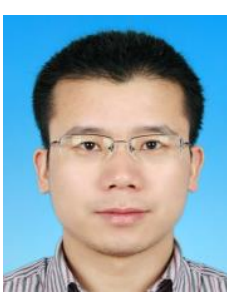

Weixing Lin (M'13) obtained his B.E. and $\mathrm{PhD}$ degrees in electrical engineering from Huazhong University of Science and Technology (HUST), China, in 2008 and 2014 respectively. He was a research fellow at University of Aberdeen during 2012-2016. 
This paper is a post-print of a paper accepted for publication in IEEE Journal of Emerging and Selected Topics in Power Electronics and is subject to Institution of Electrical and Electronic Engineering Copyright. The copy of record is available at IEEE Xplore Digital Library

He is currently the chief engineer of HVDC division at TBEA China Xinjiang Sunoasis Co. Ltd. His research interests are HVDC, MMC, dc-dc autotransformer, DC grids. 